\title{
Prostaglandins Regulate the Synthesis and Secretion of the Atrial Natriuretic Peptide
}

\author{
David G. Gardner*‡ and Harold D. Schultz ${ }^{\text {in }}$ \\ ${ }^{*}$ Metabolic Research Unit, ${ }^{8}$ Cardiovascular Research Institute, and Departments of ${ }^{\ddagger}$ Medicine and "Physiology, \\ University of California at San Francisco, San Francisco, California 94143
}

\begin{abstract}
We have examined the effects of several PGs on the synthesis and release of the atrial natriuretic peptide (ANP) in vivo and in vitro. $\mathbf{P G F}_{2 \alpha}$ infusion in anesthetized rats resulted in a significant increase in plasma immunoreactive (ir) ANP levels in vivo despite effecting only modest changes in hemodynamics. The PGs were also effective at promoting irANP secretion in primary cultures of neonatal rat atrial and ventricular cardiocytes. PGF ${ }_{2 \alpha}$ increased irANP release with half-maximal induction seen at $\sim 1^{-8} \mathrm{M} ; \mathrm{PGE}_{2}$ was somewhat less effective and prostacyclin (PGI ${ }_{2}$ ) was without effect. The PGs also increased ANP mRNA levels in these cells, suggesting that these agents exert a major effect on the synthesis as well as the secretion of the prohormone. Transient expression analysis of atrial cells transfected with 2,500 bp of human (h) ANP 5 flanking sequence linked to a chloramphenicol acetyltransferase (CAT) reporter demonstrated that $\mathrm{PGF}_{2 \alpha}\left(10^{-5} \mathrm{M}\right)$ increased hANP promoter activity approximately twofold relative to the control. PGF $_{2 \alpha}$ had no effect on the promoterless control ( $\mathrm{pSV}_{0}$-lamin $\mathrm{CAT}$ ). Treatment of cultured atriocytes with high concentrations of a cyclooxygenase inhibitor resulted in a significant suppression of ANP secretion in vitro and a truncation of the plasma ANP response to volume infusion in vivo. Taken together these studies support a role for PGs as regulators of cardiac ANP synthesis and secretion, and suggest an additional mechanism whereby eicosanoids may act to control cardiovascular and renal homeostasis. (J. Clin. Invest. 1990. 86:52-59.) Key words: atrial natriuretic peptide $\bullet$ prostaglandins • secretory control
\end{abstract}

\section{Introduction}

The atrial natriuretic peptide (ANP) ${ }^{1}$ is a peptide hormone that possesses potent bioactivity in the cardiovascular and renal systems $(1,2)$. Secretion of this peptide by the cardiac

Address correspondence to Dr. David G. Gardner, Metabolic Research Unit, Department of Medicine, University of California, San Francisco, Box 0516, HSE 671, San Francisco, CA 94143.

Received for publication 15 June 1989 and in revised form 7 March 1990

1. Abbreviations used in this paper: ANP, atrial natriuretic peptide; CAT, chloramphenicol acetyltransferase; CVP, central venous pressure; 5'FS, $5^{\prime}$ flanking sequence; h, human; HR, heart rate; IBMX, isobutylmethylxanthine; irANP, immunoreactive ANP; MAP, mean arterial blood pressure; proANP, ANP prohormone.

J. Clin. Invest.

(c) The American Society for Clinical Investigation, Inc.

0021-9738/90/07/0052/08 \$2.00

Volume 86, July 1990, 52-59 atria is regulated by a number of hormones (3-6) and neurotransmitters $(7,8)$, as well as by factors that affect myocardial wall tension (9-11).

PGs are eicosanoid products of arachidonic acid metabolism produced by the enzyme cyclooxygenase. They are known to affect a variety of intracellular second messenger systems, possibly through interaction with specific PG receptors on the cell surface (12). They are important regulators of cardiovascular and renal physiology with potent effects on platelet function, vascular reactivity, renal blood flow, and the handling of salt and water in the kidney (13). PGs have largely been excluded as playing an important role in mediating ANP bioactivity (14-16), but their role in regulating ANP release has been studied only to a limited degree (17).

This study was designed to investigate the regulation of immunoreactive ANP (irANP) secretion and ANP gene expression by the PGs in vivo and in vitro, and to assess the potential role of cyclooxygenase products in mediating stretch-induced ANP secretion. The findings support the hypothesis that PGs stimulate irANP release directly at the level of the myocardial cell and suggest their involvement in promoting stretch-dependent release of the hormone.

\section{Methods}

Materials. Restriction enzymes, $S_{1}$ nuclease, and calf intestinal alkaline phosphate were purchased from Bethesda Research Laboratories (Gaithersburg, MD) or Boehringer Mannheim Biochemicals (Indianapolis, IN); [ ${ }^{32}$ P]ATP was from ICN Nutritional Biochemicals (Cleveland, $\mathrm{OH}$ ); PGs, indomethacin, and naproxen were from Sigma Chemical Co. (St. Louis, MO); and meclophenamate was purchased from Biomol Research (Plymouth Meeting, PA).

In vivo studies. Female Sprague-Dawley rats (250-350 g) were anesthetized with $2 \%$ chloralose and $25 \%$ urethane $(3 \mathrm{ml} / \mathrm{kg}$ i.p.). An intra-arterial PE-50 catheter was placed in the left carotid artery for measurement of mean arterial blood pressure (MAP). Catheters were also introduced into the right internal jugular vein for the measurement of central venous pressure (CVP) and into the left femoral vein for administration of volume and pharmacological agents. Catheter patency was maintained with periodic administration of heparinized saline.

To examine the effects of intravenous administration of $\mathrm{PGF}_{2 \alpha}$ on circulating ANP levels, the following protocol was used (Fig. $1 \mathrm{~A}$ ). $1 \mathrm{ml}$ of blood was collected in $10 \mathrm{mM}$ EDTA at time 0 and placed on ice. 1 min later $0.5 \mathrm{ml}$ of normal saline (vehicle) was given into the femoral line over $60 \mathrm{~s}$. A second 1-ml blood sample was taken 5 min later. After $15 \mathrm{~min}$ a third blood sample was drawn. $1 \mathrm{~min}$ later $\mathrm{PGF}_{2 \alpha}(1 \mathrm{mg} / \mathrm{kg}$ in $0.5 \mathrm{ml}$ of saline) was delivered into the femoral line. $1-\mathrm{ml}$ blood samples were taken 1 and $4 \mathrm{~min}$ later. Blood volume was replaced with an equal volume of normal saline. MAP, CVP, and heart rate (HR) were measured throughout the course of the experiment.

For the volume expansion studies anesthetized rats were instrumented as described above to monitor MAP, CVP, and HR. A 1-ml blood sample was taken at time 0 and processed as described above. After $1 \mathrm{~min}$ an infusion of $5 \mathrm{~cm}^{3}$ of saline was delivered into the 

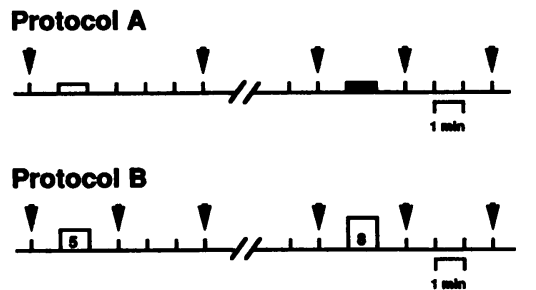

Figure 1. Experimental protocols describing the administration of PGF $_{2 \alpha}($ protocol $A)$ or volume infusion (proto$\operatorname{col} B)$ in anesthetized rats. Protocol A: open bar represents delivery of vehicle $(0.5 \mathrm{ml}$ of normal saline) alone; solid bar represents PGF $_{2 \alpha}(1 \mathrm{mg} / \mathrm{kg})$ in the same volume of vehicle. Protocol B: open bars represent the 5- and 8-ml volume infusions, respectively; arrows indicate times at which plasma samples were taken for irANP measurement.

femoral vein over a 60 -s period. Additional blood samples were taken 1 and $4 \mathrm{~min}$ later. After a 30-45-min re-equilibration period a fourth blood sample was taken. 1 min later an $8-\mathrm{cm}^{3}$ saline infusion was delivered over $60 \mathrm{~s}$. Blood samples were taken 1 and $4 \mathrm{~min}$ later. This protocol is schematicized in Fig. $1 \mathrm{~B}$. For the indomethacin-treated group the drug $\left(1 \mathrm{mg} / \mathrm{kg}\right.$ in $\left.0.1 \mathrm{M} \mathrm{Na}_{2} \mathrm{CO}_{3}\right)$ was administered $30 \mathrm{~min}$ before the $5-\mathrm{cm}^{3}$ infusion.

Blood samples were centrifuged and plasma was decanted. $0.5 \mathrm{ml}$ of plasma was extracted over a Sep-Pac C-18 column as described by Lang et al. (9) and dried under a nitrogen stream. The dessicated material was resuspended in $250 \mu \mathrm{l}$ of buffer and duplicate $100-\mu \mathrm{l}$ aliquots were assayed for irANP as described previously (18).

Cell isolation and culture. Neonatal rat cardiocyte primary cultures, enriched for either atrial or ventricular cells, were prepared as described previously (5) using a modification of the protocol of Simpson and Savion (19). Cells were cultured for $72 \mathrm{~h}$ in DME H21 containing $10 \%$ FCS and $0.1 \mathrm{mM}$ bromodeoxyuridine, followed by $48 \mathrm{~h}$ in DME H21 containing 5\% serum substitute lacking thyroxine and cortisol (20), 5\% stripped serum previously treated to remove endogenous thyroid and steroid hormone (21), $5 \mu \mathrm{g} / \mathrm{ml}$ insulin, $5 \mu \mathrm{g} / \mathrm{ml} \mathrm{transferrin,}$ and $750 \mathrm{nM}$ vitamin $B_{12}$. Cells $\left(15 \times 10^{3} /\right.$ well) were then subjected to the individual treatments described below in $200 \mu \mathrm{l}$ of serum-free DME H21 medium containing 10\% serum substitute, insulin, transferrin, and vitamin $B_{12}$. Additives were dissolved in small amounts of ethanol or dimethylsulfoxide. Similar concentrations of these solvents were added to the control media.

irANP analysis. Culture medium was collected and centrifuged at $11,000 \mathrm{~g}$ for $15 \mathrm{~s}$ to remove any cellular debris. The supernatant was decanted and stored frozen at $-20^{\circ} \mathrm{C}$ until assayed. RIA was performed essentially as described previously (5).

Size-exclusion HPLC analysis was carried out using a Bio-Sil Tsk-125 column (Bio-Rad Laboratories, Richmond, CA). 20- $\mu$ l samples were applied directly and eluted isocratically with $0.1 \mathrm{M} \mathrm{Na}_{2} \mathrm{SO}_{4}$ and $0.02 \mathrm{M} \mathrm{NaH}_{2} \mathrm{PO}_{4}, \mathrm{pH} 6.8$, containing $0.1 \%$ Triton X-100 at a flow rate of $1 \mathrm{ml} / \mathrm{min}$. The $0.5-\mathrm{ml}$ fractions were monitored for irANP by RIA. ANP prohormone (proANP) was one-tenth as effective as ANP in displacing ${ }^{125} \mathrm{I}-\mathrm{ANP}$ from the antibody. ProANP levels were corrected for this difference in immunoreactivity. The elution positions of proANP and ANP were determined using ${ }^{125}$ I-labeled recombinant human (h) proANP and rat ANP. Additional unlabeled protein standards were also used to calibrate the column.

Where appropriate, RIA data were subjected to analysis of variance and the Newman-Keuls test for significance.

$R N A$ extraction and analysis. Cytoplasmic RNA was isolated and ANP mRNA transcripts were quantitated by nuclease $S 1$ protection as described previously (5).

Transfection of hANF chloramphenicol acetyltransferase (CAT) constructions. Plasmid construction for $\mathrm{pSV}_{\mathrm{o}}$-lamin $\mathrm{CAT}$ and $p(-2,500)$-hANP CAT have been described previously (22). The former is a promoterless construct in which the SV40 enhancer and promoter elements have been deleted (23) and replaced with a 400-bp fragment from the human lamin cDNA (22). The $p(-2,500)$-hANP CAT construction contains 2,500 bp of hANP gene $5^{\prime}$ flanking se- quence (5'FS; Eco $\mathrm{RI}_{-2,500}$ to $\mathrm{Hae}^{\mathrm{III}}+\mathrm{H}_{+17}$ ) positioned in a transcriptionally correct orientation upstream from the CAT coding sequences. Previous studies demonstrated that transcription from this chimeric construction arises from the expected start site (22).

Before plating, atrial or ventricular cardiocyte-enriched cell populations were allocated into batches of $15 \times 10^{6}$ cells, pelleted, washed once in cold PBS containing $0.1 \%$ glucose, resuspended in $0.4 \mathrm{ml}$ of the same solution at room temperature, and then transfected with $50 \mu \mathrm{g}$ of supercoiled $\mathrm{pSV}_{\mathrm{o}}$-lamin CAT or $\mathrm{p}(-2,500)$-hANF CAT by electroporation (24) with $280 \mathrm{~V}$ at $250 \mu \mathrm{F}$ capacitance using a gene pulsar with capacitance extender (Bio-Rad Laboratories). Cells were incubated for 15 min at room temperature, then transferred to DME H21 containing $10 \%$ FCS and cultured in $100-\mathrm{mm}$ dishes for $60 \mathrm{~h}$. At that point the medium was changed to DME $\mathrm{H} 21$ containing $10 \%$ serum substitute plus transferrin, insulin, and vitamin $\mathrm{B}_{12}$ as described above. PGF $_{2 \alpha}$ or vehicle was added to each plate and the incubations were continued for $8 \mathrm{~h}$. At that point cells were collected, cytoplasmic extracts were made, and equivalent quantities of cytoplasmic protein were assayed for CAT activity by TLC as described (22). Levels of the acetylated forms of chloramphenicol were quantitated by identifying, excising, and counting (by liquid scintillation) the appropriate spot(s) on the TLC plate.

\section{Results}

To assess the role of eicosanoids in the regulation of ANP secretion, we examined the effect of intravenous administration of $\mathrm{PGF}_{2 \alpha}(1 \mathrm{mg} / \mathrm{kg})$ on the levels of circulating irANP in vivo. As shown in Fig. $2 A$, PGF $_{2 \alpha}$ effected a significant increase in plasma irANP levels within 2 min of administration. Infusion of an equivalent volume of normal saline was without effect. $\mathrm{PGF}_{2 \alpha}$ administration also effected modest increases in MAP and CVP, although neither was statistically significant relative to the preinfusion (i.e., time 0 ) levels in the same (i.e., $\mathrm{PGF}_{2 \alpha}$-treated) group. $\mathrm{HR}$, on the other hand, decreased sig-
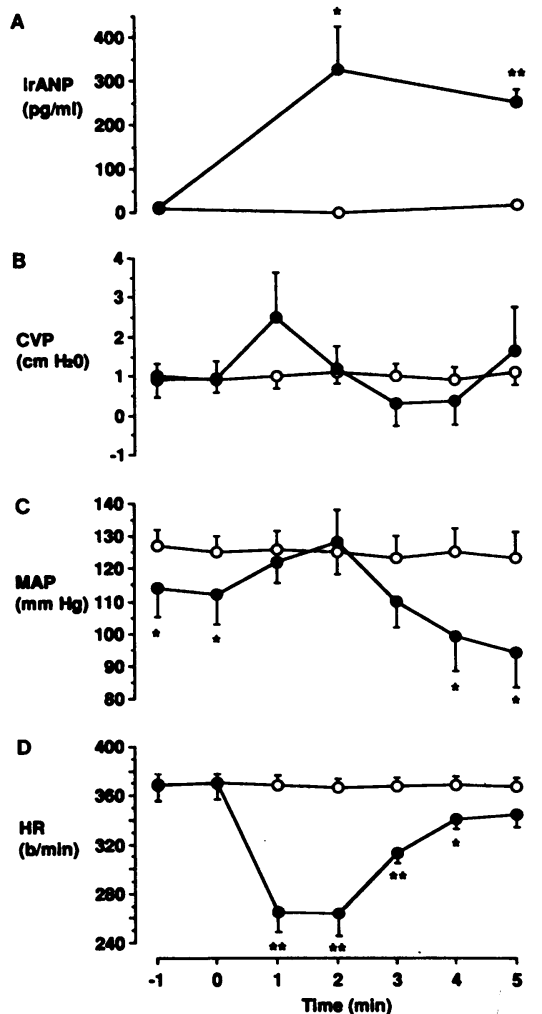

Figure 2. Effect of PGF $_{2 \alpha}$ on plasma ANP levels in vivo. $\mathrm{PGF}_{2 \alpha}(1$ $\mathrm{mg} / \mathrm{kg}$ i.v.) was administered according to the protocol described in Fig. 1. Plasma samples were taken at the times indicated and assayed for irANP. Simultaneous measurements of CVP, MAP, and HR are presented below. Points represent the mean \pm SEM for control (0) or PGF ${ }_{2 \alpha}$-treated (๑) animals. ${ }^{*} P<0.05, * * P$ $<0.01$ compared with control measured at the same time point. 
nificantly $(P<0.001)$ relative to the preinfusion control. While the modest changes in CVP and MAP are unlikely to account for the eicosanoid's effects on plasma ANP levels (see below), they make it difficult to ascribe the increase unequivocally to a direct action of the PG on the atrial cardiocyte.

To address the latter issue we examined the effects of several PGs on the secretion of irANP in primary cultures of neonatal rat atrial cardiocytes. As shown in Fig. 3, the PGs proved to be potent stimulators of irANP release. $\mathrm{PGF}_{2 \alpha}$ effected a dose-dependent increase in release of irANP from these cultures after $24 \mathrm{~h}$ of incubation (Fig. $3 \mathrm{~A}$ ). It is noteworthy that the inclusion of isobutylmethylxanthine (IBMX), a phosphodiesterase inhibitor that amplifies agonist-stimulated cAMP accumulation in a number of systems, resulted in a partial reduction rather than an amplification of the $\mathrm{PGF}_{2 a}$ effect. irANP in the atrial cell culture media increased as a function of time (Fig. $4 \mathrm{~A}$ ) in the presence or absence of $\mathrm{PGF}_{2 \alpha}$. The secretagogue effect of the PG was apparent after $24 \mathrm{~h}$ of exposure to the drug and remained statistically significant thereafter. $\mathrm{PGE}_{2}$ (Fig. $3 \mathrm{~B}$ ) had a more modest effect on irANP release, while prostacyclin $\left(\mathrm{PGI}_{2}\right.$, Fig. $3 C$ ) had no effect on ANP secretion under the conditions examined.
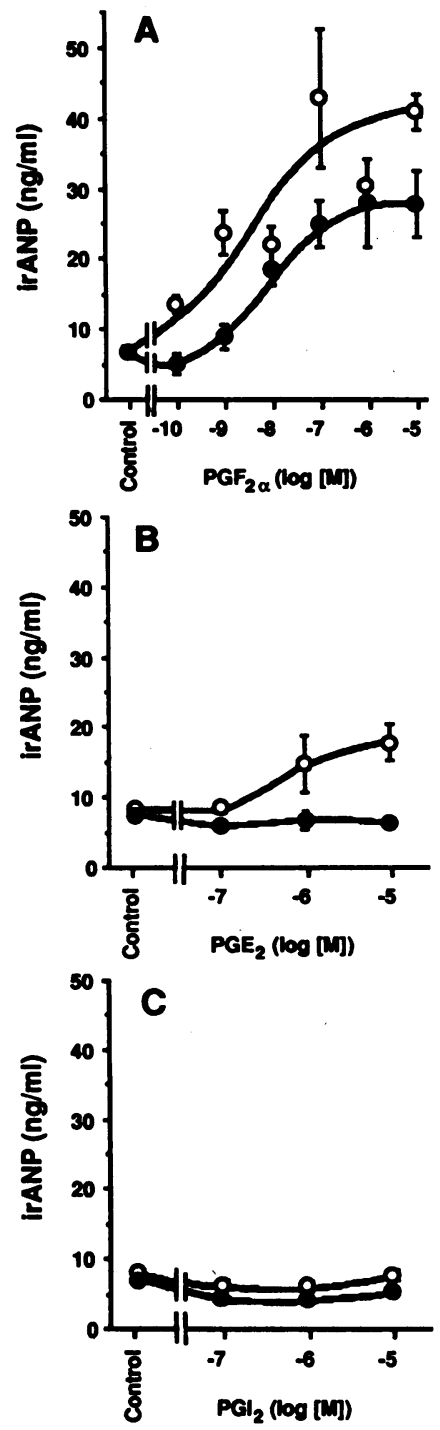

Figure 3. Effect of PGs on release of irANP from atrial cardiocytes. Cells were incubated for $24 \mathrm{~h}$ in serum-free medium containing PG, at the concentrations indicated, in the presence $(\bullet)$ or absence $(0)$ of IBMX $\left(3 \times 10^{-4} \mathrm{M}\right)$. Points represent the mean $\pm \mathrm{SEM}$. $\mathrm{PGF}_{2 \alpha}$ and $\mathrm{PGE}_{2}$ at $10^{-5} \mathrm{M}$ were each statistically different from the control $(P<0.01$ for each comparison), as well as from PGF $_{2 \alpha}+$ IBMX and $\mathrm{PGE}_{2}+$ IBMX, respectively $(P$ $<0.01$ for each comparison).
Several laboratories have shown previously that primary cultures of neonatal cardiocytes release predominately proANP into the culture medium $(25,26)$. To provide assurance that the PGs were increasing media irANP by stimulating release of cellular proANP, rather than by stimulating the processing of proANP to another, more immunoreactive, ANP form, HPLC analysis of culture media was carried out. As shown in Fig. $4 \mathrm{~B}$, the bulk of irANP in either the control or the $\mathrm{PGF}_{2 \alpha}$-treated cells migrated with proANP, arguing against a significant effect of the PG on the conversion of proANP to ANP.

The reduction of $\mathrm{PGF}_{2 \alpha}$-stimulated irANP release in the presence of the phosphodiesterase inhibitor IBMX and the lack of effect of $\mathrm{PGI}_{2}$, an eicosanoid that appears to function predominantly through activation of adenylate cyclase, suggest that the stimulatory effect is not mediated through a cAMP-dependent mechanism. To explore this further we examined the effects of two cAMP-dependent agonists on irANP secretion. As shown in Fig. 5, administration of either 8bromo-cAMP or forskolin, a direct activator of the membrane-bound adenylate cyclase, resulted in an inhibition of basal irANP release. Similarly, when forskolin was administered coincident with $\mathrm{PGF}_{2 \alpha}$, a modest reduction in agonist activity was seen. Taken together, these findings support the hypothesis that PG-mediated increments in irANP release do not operate through a cAMP-dependent mechanism. They also suggest that under the experimental conditions used in these studies, cAMP may act to suppress rather than stimulate ANP secretion.

To explore the mechanism of the $\mathrm{PGF}_{2 \alpha}$ effect further we assessed the capacity of the eicosanoid to synergize with other secretogogues in promoting ANP release. As shown in Fig. 6 A, inclusion of increasing concentrations of potassium ion alone in the culture medium led to a dose-dependent increment in irANP release. Addition of $\mathrm{PGF}_{2 \alpha}$ resulted in a further increase in irANP release at each concentration of extracellular potassium, suggesting that these agents act through independent pathways in promoting granule release. The $\mathrm{PGF}_{2 \alpha}$ effect was not dependent on the presence of calcium in the culture medium (Fig. $6 \mathrm{~B}$ ). The stimulatory effect was easily demonstrated in calcium-free medium (endogenous calcium $<100$ $\mu \mathrm{M})$, although the magnitude was somewhat reduced relative to that seen in the presence of exogenous calcium chloride.

Stimulation of irANP secretion was not confined to atrial cardiocytes. Treatment of ventricular cardiocyte-enriched cultures (Table I) with either $\mathrm{PGF}_{2 \alpha}$ or $\mathrm{PGE}_{2}$ resulted in a dosedependent stimulation of irANP release similar to that found with the atriocytes. Although the basal secretion was considerably lower in the ventricular cardiocytes relative to the atrial cells, a threefold increase in irANP release was seen at the highest $\left(10^{-5} \mathrm{M}\right) \mathrm{PGF}_{2 \alpha}$ concentration.

The effect on secretion of irANP was paralleled by an increase in the expression of the rat ANP gene. As shown in Fig. 7 , treatment with $\mathrm{PGF}_{2 \alpha}$ or $\mathrm{PGE}_{2}$ resulted in a stimulation of ANP mRNA levels over a dose range that was similar to that found for secretion of the peptide. Again the effect was apparent in atrial (Fig. $7 \mathrm{~A}$ ) and ventricular (Fig. $7 \mathrm{~B}$ ) cells, implying similar regulation in both myocardial cell populations.

To assess the locus of the PG-mediated increase in rANP gene expression, we transfected chimeric constructions containing $\sim 2,500$ bp of human ANP 5'FS linked to a bactérial CAT reporter into primary cultures enriched for atrial cardio- 
A

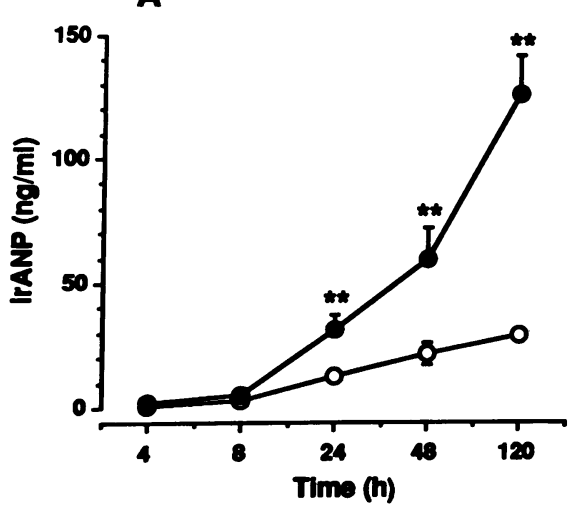

B

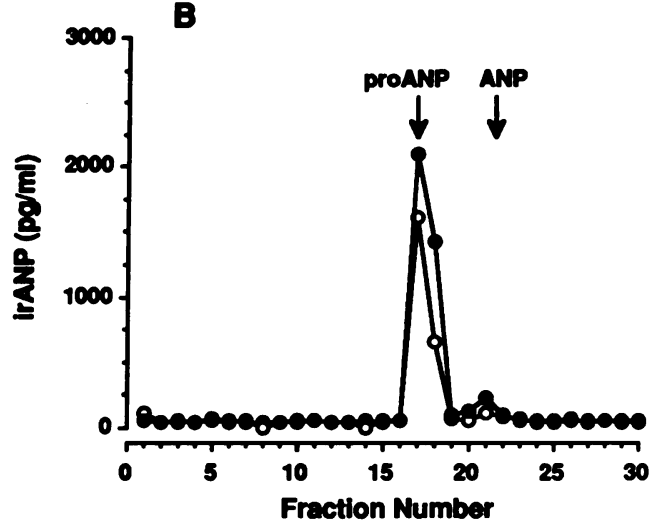

Figure 4. A, Time course of $\mathrm{PGF}_{2 \alpha}$ effects on ANP secretion. Cells were cultured for varying periods of time in serum-free media in the presence (•) or absence (0) of $\mathrm{PGF}_{2 \alpha}\left(10^{-6}\right.$ M). Medium was collected and cumulative irANP measured by RIA. Points represent the mean \pm SEM. $* * P<0.01 . B$, HPLC analysis of media irANP from cells cultured in serum-free medium in the presence (•) or absence (o) of $\mathrm{PGF}_{2 \alpha}\left(10^{-6}\right.$ M) for $24 \mathrm{~h}$. Migration positions of proANP and ANP (arrows) were determined with iodinated standards run in parallel. ProANP levels have been corrected for reduced cross-reactivity (vs. ANP) in the RIA. cytes and tested the acute transfectants for sensitivity to PG. As shown in Fig. $7 C$, treatment for $24 \mathrm{~h}$ with $\mathrm{PGF}_{2 \alpha}$ increased CAT expression in transfected atrial cells approximately twofold. No effect of the PG was noted in cells transfected with the promoterless $\mathrm{pSV}_{\mathrm{o}}$-lamin CAT.

Next, we asked whether endogenous PG production contributes significantly to the basal release of irANP in the cardiocyte primary cultures. As shown in Fig. 8, high concentrations $\left(10^{-4} \mathrm{M}\right)$ of meclophenamate, naproxen, or indomethacin resulted in significant reductions in irANP release. These findings imply that PG production, even in these static cultures, may play a role in maintaining basal irANP secretion.

Finally, we asked whether PGs might play a role in fostering stretch-induced release of the peptide from the cardiac atria. Several groups (27-29) have identified significant levels of PGs in atrial tissue, and stretch has been shown to increase $P G$ release in a number of other systems $(30,31)$. To approach this question we used the protocol outlined in Fig. $1 B$ to volume-expand anesthetized rats in vivo, monitoring the changes in plasma ANP levels as a function of changes in MAP and CVP. As shown in Fig. 9, pretreatment of rats with indomethacin $(1 \mathrm{mg} / \mathrm{kg})$ resulted in a $\sim 50 \%$ reduction in the increment in plasma irANP levels 2 and $5 \mathrm{~min}$ after an $8-\mathrm{cm}^{3}$ volume infusion, supporting a role for endogenous PG production in regulating or modulating the ANP secretory response to increased atrial tension. This attenuation of the plasma ANP response to volume infusion occurred despite the fact that the changes in CVP and MAP were very similar in the indomethacin-treated and control animals.

\section{Discussion}

The findings presented above demonstrate that the PGs, particularly $\mathrm{PGF}_{2 \alpha}$, are capable of increasing ANP secretion in vivo and in vitro, lending further support to the importance of these agents in the regulation of fluid and electrolyte balance and cardiovascular homeostasis $(1,3)$. Although $\mathrm{PGF}_{2 \alpha}$ administration resulted in modest changes in CVP and MAP in our in vivo preparation, it does not seem likely that these changes alone could account for the increase in plasma ANP. As shown in Fig. $9 A$, a $5-\mathrm{ml}$ volume infusion resulted in similar alterations in hemodynamics without significantly affecting plasma ANP levels. These findings imply that at least a portion of the $\mathrm{PGF}_{2 \alpha}$ effect is independent of changes in central hemodynamics. The in vitro studies support an interaction directly at the level of the myocardial cell. While the absolute
A

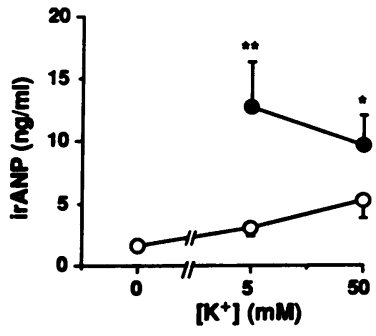

B

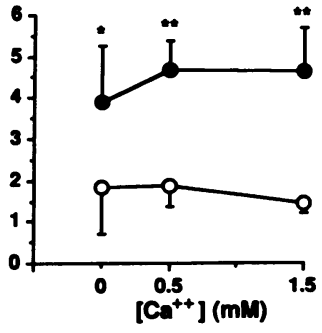

Figure 6. Effect of variable extracellular cation concentration on PGF $_{2 \alpha}$-mediated secretion of irANP. $A$, Atrial cardiocytes were incubated with varying concentrations of medium $\mathrm{KCl}$ in the presence (๑) or absence (0) of $\mathrm{PGF}_{2 \alpha}\left(10^{-6} \mathrm{M}\right) . B$, Atrial cells were incubated with different concentrations of exogenous $\mathrm{CaCl}_{2}$ in the presence (๑) or absence (o) of $\mathrm{PGF}_{2 \alpha}\left(10^{-6} \mathrm{M}\right)$. Medium samples were collected after $24 \mathrm{~h}$ and assayed for irANP. Points represent the mean \pm SD. ${ }^{*} P$ $<0.05,{ }^{* *} P<0.01$ relative to control point at the same cation concentration. irANP release at $50 \mathrm{mM} \mathrm{KCl}$ was also different from that at $0 \mathrm{mM} \mathrm{KCl}$ in the absence of $\mathrm{PGF}_{2 \alpha}, P<0.05$. 
Table I: Effect of PGF $F_{2 \alpha}$ and $P G E_{2}$ on Release of irANP from Ventricular Cardiocytes

\begin{tabular}{cl}
\hline Sample & \multicolumn{1}{c}{ irANP } \\
\hline & $n g /$ ml per $24 h$ \\
Control & $20.5 \pm 5.9$ \\
PGE $_{2}$ & $12.6 \pm 9.9$ \\
$10^{-7} \mathrm{M}$ & $36.5 \pm 5.5^{*}$ \\
$10^{-6} \mathrm{M}$ & $43.6 \pm 7.2^{\ddagger}$ \\
$10^{-5} \mathrm{M}$ & \\
$\mathrm{PGF}_{2 \alpha}$ & $45.3 \pm 15.1^{\ddagger}$ \\
$10^{-7} \mathrm{M}$ & $49.5 \pm 8.4^{\ddagger}$ \\
$10^{-6} \mathrm{M}$ & $63.8 \pm 5.2^{\ddagger}$ \\
$10^{-5} \mathrm{M}$ &
\end{tabular}

Cells were cultured for $24 \mathrm{~h}$ in serum-free media in the presence of increasing concentrations of the PGs. Media were collected and irANP was quantitated by RIA. Results are expressed as mean \pm SD. ${ }^{*} P<0.05 ;{ }^{\ddagger} P<0.01$ relative to the control.

magnitude of the $\mathrm{PGF}_{2 \alpha}$ induction in vitro varied from 2- to as much as 10-fold, the stimulatory effect was consistently found in each of six individual experiments (data not shown). $\mathrm{PGE}_{2}$ occasionally gave statistically significant responses of a similar magnitude, but in general, as shown in Fig. $2 \mathrm{~B}$, the effect was $\sim 50 \%$ of that seen with PGF $_{2 \alpha}$. In addition, higher doses of $\mathrm{PGE}_{2}\left(10^{-5}\right.$ vs. $10^{-7} \mathrm{M}$ for $\left.\mathrm{PGF}_{2 \alpha}\right)$ were required to achieve maximal secretion. We also tested $\mathrm{PGI}_{2}$ (prostacyclin) for effects on release of the peptide and/or ANP mRNA level and found none; however, given the very short half-life of this agent in many biological systems and the extended time course of most of our studies, a possible role for $\mathrm{PGI}_{2}$ in the regulation of ANP secretion and/or gene expression cannot be excluded with certainty.

PGs are known to function through a number of different second messenger pathways. The best studied among these is the activation of adenylate cyclase (32), presumably through a PG receptor on the cell surface. In general, PGs of the E series are more effective than those of the $F$ series in promoting this activation (32). Noteworthy, inclusion of IBMX at concentrations that promote agonist-stimulated cAMP accumulation in other systems resulted in a reduction in irANP release, implying that, if anything, intracellular cAMP may act to reduce rather than stimulate secretion of the peptide in the presence of the PG. This hypothesis is supported by the fact that 8bromo-cAMP and forskolin, two agents that promote cAMPdependent activity through separate mechanisms, reduced basal irANP release, and in the latter case $\mathrm{PGF}_{2 \alpha}$-stimulated release, from atrial cardiocyte cultures. By inference this would suggest that an alternative second messenger system (e.g., intracellular calcium or phosphoinositide turnover) is involved in mediating the PG effect.

Effects of $\mathrm{PGF}_{2 \alpha}$ on irANP secretion were first evident after $24 \mathrm{~h}$, a time point that is probably dominated by effects on synthesis rather than release of preformed storage pools. The absence of stimulation at the earlier time points probably reflects the lack of sensitivity of our assay system in detecting small changes in secretory activity. In recent pilot studies, using atriocytes cultured on an extracellular matrix, we have been able to demonstrate PGF $_{2 \alpha}$-mediated increments in secretory activity within $15 \mathrm{~min}$ of administration of the eico-
A

B $\begin{array}{lllllll}1 & 2 & 3 & 4 & 5 & 6 & 7\end{array}$

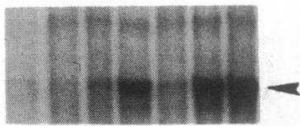

$\begin{array}{lllllll}1 & 2 & 3 & 4 & 5 & 6 & 7\end{array}$

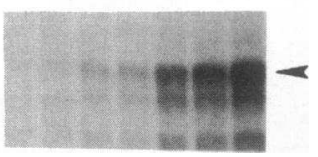

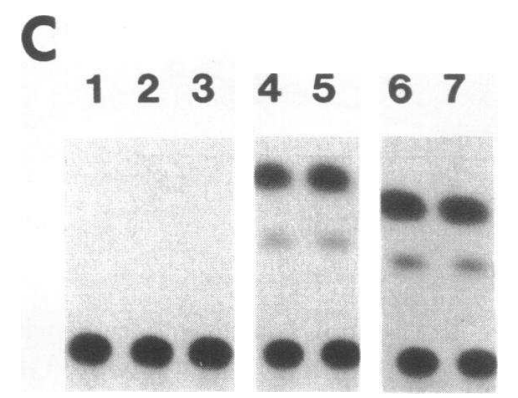

Figure 7. Effect of PGs on the expression of the ANP gene. Atrial $(A)$ or ventricular $(B)$ cardiocytes were treated for $24 \mathrm{~h}$ with vehicle alone (lane 1), $\mathrm{PGE}_{2}$ at $10^{-7} \mathrm{M}$ (lane 2), $10^{-6} \mathrm{M}$ (lane 3), or $10^{-5} \mathrm{M}$ (lane 4), or $\mathrm{PGF}_{2 \alpha}$ at $10^{-7} \mathrm{M}$ (lane 5), $10^{-6} \mathrm{M}$ (lane 6), or $10^{-5} \mathrm{M}$ (lane 7). RNA was isolated and analyzed by nuclease $S_{1}$ protection analysis. Arrow indicates position of predominant protected band ( 195 nucleotides). Analyses run in the absence of cardiocyte RNA identified no bands in this region of the gel. $C$, Atrial cells were transfected with $\mathrm{pSV}_{\mathrm{o}}$-lamin CAT (lanes $\left.1-3\right)$ or $\mathrm{p}(-2,500)$-hANP CAT (lanes 4-7) and cultured for $60 \mathrm{~h}$. Cells were treated with vehicle alone (lanes 1, 4, and 5) or with $10^{-5} \mathrm{M} \mathrm{PGF}_{2 \alpha}$ (lanes 2, 3, 6, and 7) for an additional $8 \mathrm{~h}$ before collection. Cytoplasmic extracts were then assayed for CAT activity as described in the text. Samples were run on a single TLC plate. The lower band represents nonacetylated chloramphenicol; upper bands represent the acetylated products. Average conversion of chloramphenicol to the acetylated forms in the p(-2,500)-hANP CAT-transfected cells was $20 \%$ in the control and $36 \%$ in the PGF $_{2 \alpha}$-treated cells.

sanoid (control $=2.88 \pm 0.48 ; \mathrm{PGF}_{2 \alpha}=9.26 \pm 0.74 ;$ mean $\pm \mathrm{SD}$ in nanograms per milliliter per $15 \mathrm{~min}, P<0.01$ ), implying regulation of acute as well as chronic secretory activity. The effect on synthesis of the prohormone is supported by the demonstration of PG-increased ANP mRNA levels in both atrial and ventricular cardiocytes. The increase in ANP mRNA levels appears to derive, at least in part, from augmented transcription of the ANP gene since $\mathrm{PGF}_{2 \alpha}$ stimulated expression of chimeric constructs containing only 5 'FS from the hANP gene, devoid of any coding sequence present in the ANP mRNA transcript. Independent PG-mediated effects on

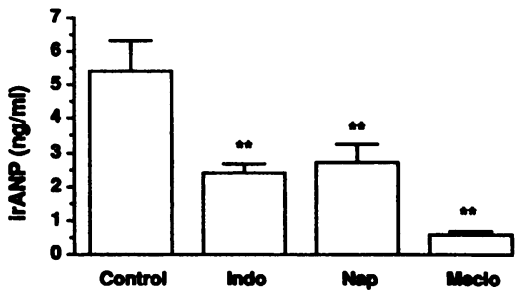

Figure 8. Effect of cyclooxygenase inhibitors on basal irANP release in vitro. Atrial cardiocytes were cultured either alone (control) or with $10^{-4} \mathrm{M}$ indometh acin, naproxen, or meclophenamate for $24 \mathrm{~h}$.

Samples were collected and assayed for irANP. Bars display the mean \pm SD. ${ }^{*} P<0.01$ relative to control. 


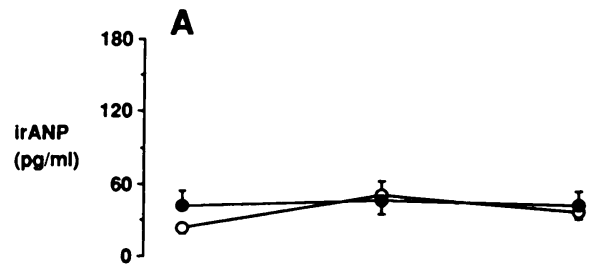

B
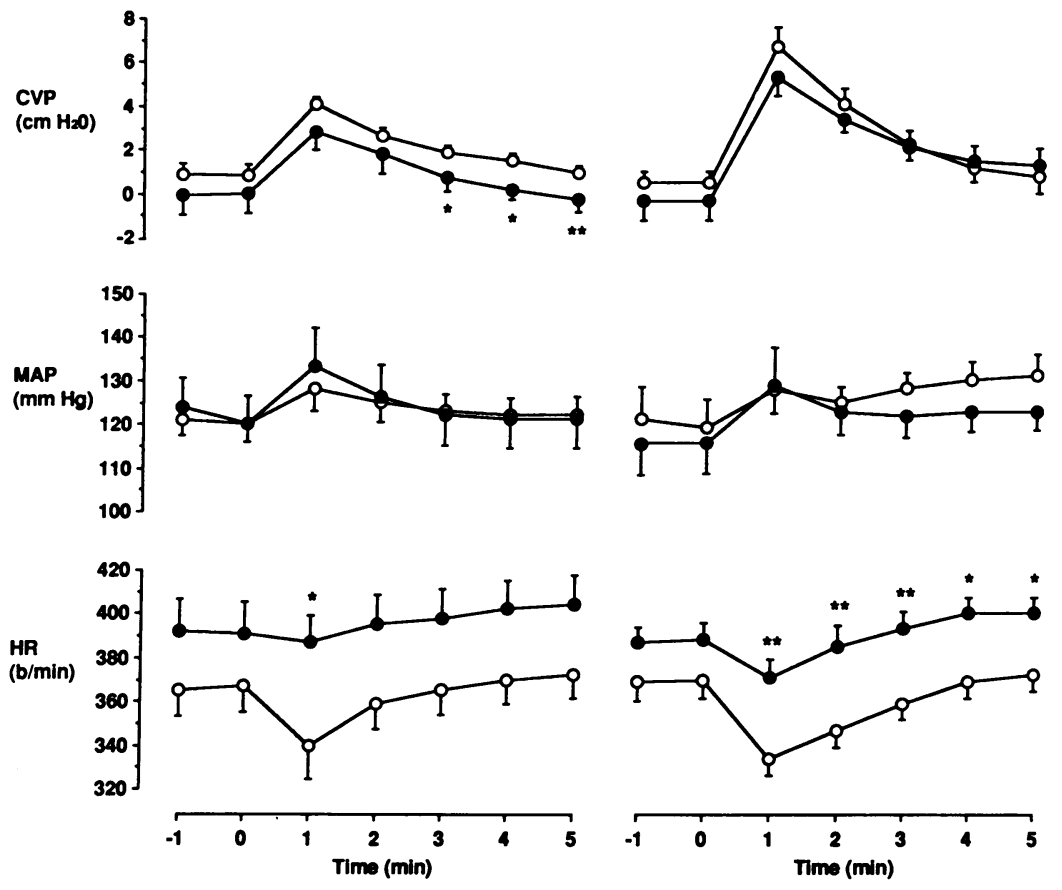

Figure 9. Effect of indomethacin on stretch-dependent release of irANP in vivo. Anesthetized rats, pretreated with indomethacin $(1 \mathrm{mg} / \mathrm{kg}$ i.v.; $\bullet)$ or vehicle alone (O), were infused sequentially with $5 \mathrm{ml}(A)$ and $8 \mathrm{ml}(B)$ of normal saline according to the protocol described in Fig. $1 B$. Samples were taken at the times indicated and assayed for irANP. Simultaneous measurements of CVP, MAP, and HR are presented below. Points represent the mean \pm SEM. ${ }^{*} P<0.05$, ${ }^{* *} P<0.01$ compared with the control sample taken at the same time point. the stability of the secreted ANP peptide or the ANP mRNA are not excluded by the present study and could contribute to their respective steady-state levels. The data also indicate that the hANP gene shares with its counterpart in the rat a sensitivity to PG stimulation, and that at least some of the recognition signals governing this stimulation at the genetic level are encoded within $\sim 2,500$ bp of $5^{\prime} \mathrm{FS}$.

These data raise some intriguing questions regarding the physiological relationship of PG production to ANP secretion. PGs are known to be released from vascular tissue in response to stretch in vitro $(30,31)$, and stretch or tension is thought to be the dominant modulator of ANP secretion from the cardiac atria in vivo $(9,10)$ and in vitro (11). In addition, the right atrium can be a significant source of endogenous PG production (27-29), raising the possibility that the PGs or related products could serve as transduction mechanisms linking tension to ANP secretion. Treatment of our cultured cardiocytes with either indomethacin, meclophenamate, or naproxen effected a modest reduction in the basal rate of irANP secretion. However, in each case the concentration of cyclooxygenase inhibitor required to demonstrate the inhibition was quite high, suggesting that, at least in our static primary cultures, basal release is not heavily PG dependent. Nevertheless, it remains possible that local production of PGs in a more physiological setting could serve as an important modulator of ANP release on either an autocrine or a paracrine basis, a hypothesis that is supported to some degree by the in vivo studies presented in Fig. 9 (see below). Loss of the capacity for PG production in myocardial (i.e., an autocrine mechanism) or mes- enchymal cells (i.e., a paracrine mechanism) due to subtle alterations in cellular physiology related to placing the cells in culture (e.g., absence of pulsatile tension) or, alternatively, to exclusion of the relevant PG-producing cell from the primary cultures, could account for the relative ineffectiveness of the cyclooxygenase inhibitors in vitro.

Another interesting finding obtained from the in vivo studies relates to the effects of the PGs on HR. As shown in Fig. 1, a modest and nonsignificant elevation in MAP seen after $\mathrm{PGF}_{2 \alpha}$ administration was accompanied by a reduction in $\mathrm{HR}$ of almost 100 beats per minute, presumably resulting from activation of the baroreceptor reflex. A similar increase in MAP seen after a 5- or 8-ml volume infusion (Fig. 9) was accompanied by a much smaller decrease in HR (i.e., $\sim 20-30$ beats per minute). More importantly, pretreatment of the animals with indomethacin eliminated the baroreceptor-mediated reflex bradycardia seen with the 5-ml infusion and severely truncated that seen with the 8-ml infusion. This suggests that PGs positively regulate or amplify signals originating in the arterial baroreceptors, structures which, like the ANP-producing cardiocytes, are responsible for transducing tension or stretch-derived information into a second effector system.

Myocardial cells may also respond to PGs carried to the heart from extracardiac sites of production (e.g., vascular endothelium or renal medulla). Under physiological conditions most PGs, with the exception of prostacyclin, are cleared in a single passage through the pulmonary circulation. However, based on data presented in Fig. 2, it is apparent that this clearance function can be saturated to some extent when large 
nonphysiological concentrations of eicosanoid are administered. These considerations take on potential relevance when one considers the underlying pathophysiology in patients with Bartter's syndrome (33). Bartter's syndrome is a clinical disorder characterized by hypovolemia, hypokalemia, normal blood pressure, vascular resistance to angiotensin and other vasopressors, an abnormality in renal chloride handling, and an elevation in renal PG production. These patients have also been shown to have inappropriately elevated plasma ANP levels (34-36). The combination of hypovolemia, elevated ANP levels, increased PG production, and reversibility of each these features with indomethacin treatment suggests that the elevations in plasma ANP could result from overproduction of renal PGs in these patients (34-36). The findings described in this study raise the intriguing possibility that such an effect could arise from direct stimulation of the ANP-producing atrial cardiocytes by PGs produced in the kidney. It is also noteworthy that a number of features of the syndrome (e.g., hypovolemia and resistance to vasopressor bioactivity) which have, in large part, been attributed to the PGs, represent biological effects that are shared in common with ANP. Overproduction of ANP could serve to amplify PG-dependent activity at the periphery and contribute to the phenotype of the syndrome.

In summary, we have demonstrated that PGs have a direct stimulatory effect on ANP secretion and ANP gene expression in primary cultures of myocardial cells. Our findings suggest that these eicosanoids may play an important role in the physiological mechanism linking stretch to ANP release. PG-mediated ANP release may also be of importance in pathophysiological states characterized by PG overproduction, either locally (e.g., in ischemic myocardium) or in extracardiac sites (e.g., the renal medulla).

\section{Acknowledgments}

We gratefully acknowledge the technical assistance of Mr. K. Nakamura, Ms. B. Hedges, Mr. R. Brown, Mr. A. Dangel, and Ms. K. Nguyen. The authors are grateful to Mrs. A. Bull for preparation of the manuscript and to Dr. J. D. Baxter for his careful review of the text. Dr. $R$. Scarborough of California Biotechnology Inc. generously provided the human proANP.

This study was supported by National Institutes of Health grants HL-35753 and HL-33797, and by a Grant-in-Aid from the American Heart Association with partial support from the Redwood Empire Chapter. Dr. Gardner and Dr. Schultz are Established Investigators of the American Heart Association.

\section{References}

1. Ballerman, B. J., and B. M. Brenner. 1985. Biologically active atrial peptides. J. Clin. Invest. 76:2041-2048.

2. Cantin, M., and J. Genest. 1985. The heart and the atrial natriuretic factor. Endocr. Rev. 6:107-127.

3. Gardner, D. G., B. J. Gertz, and S. Hane. 1987. Thyroid hormone increases rat atrial natriuretic peptide messenger ribonucleic acid accumulation in vivo and in vitro. Mol. Endocrinol. 1:260-265.

4. Ladenson, P. W., K. D. Bloch, and J. G. Seidman. 1988. Modulation of atrial natriuretic factor by thyroid hormone: messenger ribonucleic acid and peptide levels in hypothyroid, euthyroid and hyperthyroid rat atria and ventricles. Endocrinology. 123:652-657.

5. Gardner, D. G., B. J. Gertz, C. F. Deschepper, and D. Y. Kim.
1988. Gene for the rat atrial natriuretic peptide is regulated by glucocorticoids in vitro. J. Clin. Invest. 82:1275-1281.

6. Ballerman, B. J., K. D. Bloch, J. G. Seidman, and B. M. Brenner. 1986. Atrial natriuretic peptide transcription, secretion and glomerular receptor activity during mineralocorticoid escape in the rat. J. Clin. Invest. 78:840-843.

7. Sonnenberg, H., and A. T. Veress. 1984. Cellular mechanism of release of atrial natriuretic factor. Biochem. Biophys. Res. Commun. 124:443-449.

8. Schiebinger, R. J., M. Z. Baker, and J. Linden. 1987. Effect of adrenergic and muscarinic cholinergic agonists on atrial natriuretic peptide secretion by isolated rat atria. J. Clin. Invest. 80:1687-1691.

9. Lang, R. E., H. Tholken, H. Ganten, F. C. Luft, H. Ruskoaho, and Th. Unger. 1985. Atrial natriuretic factor-circulating hormone stimulated by volume loading. Nature (Lond.). 314:264-266.

10. Metzler, C. H., M. E. Lee, T. N. Thrasher, and D. J. Ramsay. 1986. Increased right or left atrial pressure stimulates release of atrial natriuretic peptides in conscious dogs. Endocrinology. 119:2396-2398.

11. Schiebinger, R. J., and J. Linden. 1986. The influences of resting tension on immunoreactive atrial natriuretic peptide secretion by rat atria superfused in vitro. Circ. Res. 59:105-109.

12. Kuehl, F. A., Jr., and J. Humes. 1972. Direct evidence for a prostaglandin receptor and its application to prostaglandin measurements. Proc. Natl. Acad. Sci. USA. 69:480-484.

13. Margolius, H. S., P. V. Halushka, and J. C. Frolich. 1987 Prostaglandins, kallikreins and kinins and Bartter's syndrome. In Endocrinology and Metabolism. P. Felig, J. D. Baxter, A. E. Broadus, and L. A. Frohman, editors. McGraw-Hill, Inc. New York. 1768-1793.

14. Salazar, F. J., R. Bolterman, M. J. Fiksen-Olsen, T. Quesada, and J. C. Romero. 1988. Role of prostaglandins in mediating renal effects of atrial natriuretic factor. Hypertension (Dallas). 12:274-278.

15. Gaillard, C. A., H. A. Koomans, A. J. Rabelink, and E. J. Dorhout-Mees. 1987. Effects of indomethacin on renal response to atrial natriuretic peptide. Am. J. Physiol. 253 (Renal Fluid Electrolyte Physiol. 22):F868-F873.

16. Miyamori, I., M. Ikeda, T. Matsubara, S. Okamoto, H. Koshida, S. Yasuhara, T. Morise, and R. Takeda. 1987. The renal, cardiovascular and hormonal actions of human atrial natriuretic peptide in man: effects of indomethacin. Br. J. Clin. Pharmacol. 23:425-431.

17. Thamsborg, G., N. Keller, R. Sykulski, and T. Storm. 1988. Dynamic exercise stimulates ANF secretion by mechanisms independent of prostaglandins. Horm. Metab. Res. 20:131-132.

18. Wong, K. R., M.-W. Xie, S. Lan-Bo, F.-Y. Liu, C.-L. Huang, D. G. Gardner, and M. G. Cogan. 1988. Urinary cGMP as a biological marker of the renal activity of atrial natriuretic factor. Am. J. Physiol. 255:F1220-F1224.

19. Simpson, P., and S. Savion. 1982. Differentiation of rat myocytes in single cell cultures with and without proliferating nonmyocardial cells. Circ. Res. 50:101-116.

20. Bauer, R. F., L. O. Arthur, and D. L. Fine. 1976. Propagation of mouse mammary tumor virus in serum-free medium. In Vitro (Rockville). 12:558-563.

21. Dobner, P. R., E. S. Kawasaki, L. Yu, and F. C. Bancroft. 1981. Thyroid or glucocorticoid hormone induces progrowth hormone mRNA and its probable nuclear precursor in rat pituitary cells. Proc. Natl. Acad. Sci. USA. 78:2230-2234.

22. LaPointe, M. C., J. Wu, B. Greenberg, and D. G. Gardner. 1988. Upstream sequences confer atrial-specific expression on the human atrial natriuretic factor gene. J. Biol. Chem. 263:9075-9078.

23. Gorman, C. M., L. Moffat, and B. H. Howard. 1982. Recombinant genes which express chloramphenicol acetyltransferase. $\mathrm{Mol}$. Cell. Biol. 2:1044-1051.

24. Potter, H., L. Weir, and P. Ledèr. 1984. Enhancer-dependent expression of human kappa immunoglobulin genes introduced into mouse pre-B lymphocytes by electroporation. Proc. Natl. Acad. Sci. USA. 81:7161-7165.

25. Glembotski, C. C., and T. R. Gibson. 1985. Molecular forms of 
immunoreactive atrial natriuretic peptide released from cultured rat atrial myocytes. Biochem. Biophys. Res. Commun. 132:1008-1017.

26. Bloch, K. D., J. A. Scott, J. B. Zisfein, J. T. Fallon, N. M. Margolis, C. E. Seidman, G. R. Matsueda, C. J. Homcy, R. M. Graham, and J. G. Seidman. 1985. Biosynthesis and secretion of proatrial natriuretic factor by cultured rat cardiocytes. Science (Wash. DC). 230:1168-1171.

27. Ahumada, G. G., B. E. Sobel, and P. Needleman. 1980. Synthesis of prostaglandins by cultured rat heart myocytes and cardiac mesenchymal cells. J. Mol. Cell. Cardiol. 12:685-700.

28. Boltan, H. S., R. Chanduban, R. W. Bryant, J. M. Bailey, W. B. Weglicki, and G. V. Vahougn. 1980. Prostaglandin synthesis by adult heart myocytes. J. Mol. Cell. Cardiol. 12:1287-1298.

29. Evans, A. S., C. G. Dunkel, J. E. Saffritz, and P. Needleman. 1987. Exaggerated atrial arachidonate metabolism in rabbit left ventricular myocardial infarction. J. Clin. Invest. 79:155-162.

30. Quadt, J. F. A., R. Voss, and F. Ten-Hoor. 1982. Prostacylin production of the isolated pulsatingly perfused aorta. J. Pharmacol. Methods. 7:263-276.
31. Pohl, U., L. Dezsi, B. Simon, and R. Busse. 1987. Selective inhibition of endothelium-dependent dilation in resistance-sized vessels in vitro. Am. J. Physiol. 253:H234-H239.

32. Hall, A. K., and H. R. Behrman. 1982. Prostaglandins: biosynthesis, metabolism and mechanism of cellular action. In Prostaglandins. J. B. Lee, editor. Elsevier Science Publishing Co., Inc., New York. $1-38$.

33. Halushka, P. V., H. Wohltmann, P. J. Privitera, G. Hurwitz, and H. S. Margolius. 1977. Bartter's syndrome: urinary prostaglandin E-like material and kallikrein: indomethacin effects. Ann. Intern. Med. 78:281-286.

34. Tunny, T. J., and R. D. Gordon. 1986. Plasma atrial natriuretic peptide in primary aldosteronism (before and after treatment) in Bartter's and Gordon's syndromes. Lancet. i:272-273.

35. Gordon, R. D., T. J. Tunny, and S. A. Klemm. 1986. Indomethacin and atrial natriuretic peptide in Bartter's syndrome. N. Engl. J. Med. 315:459.

36. Sasaki, H., M. Okumura, T. Kawasaki, K. Kangawa, and H. Matsuo. 1987. Indomethacin and atrial natriuretic peptide in pseudoBartter's syndrome. N. Engl. J. Med. 316:167. 